\title{
Myrtle Leaf Oil
}

National Cancer Institute

\section{Source}

National Cancer Institute. Myrtle Leaf Oil. NCI Thesaurus. Code C107333.

The essential oil of Myrtus communis. Myrtle leaf oil is taken internally for urinary infections, digestive problems, bronchial congestion, and dry coughs. 